\title{
EXTRUSION-BASED 3D PRINTING OF MOLECULAR SIEVE ZEOLITE FOR GAS ADSORPTION APPLICATIONS
}

\author{
Nishant Hawaldar ${ }^{1}$, Hye-Young Park ${ }^{2}$, Yeon-Gil Jung ${ }^{2}$, Jing Zhang ${ }^{1}$ \\ ${ }^{1}$ Indiana University - Purdue University Indianapolis \\ ${ }^{2}$ Changwon National University, Republic of Korea
}

Keywords: Extrusion - based 3D printing, Molecular sieve zeolite, Gas adsorption

\begin{abstract}
Extrusion based 3D printing is one of the emerging additive manufacturing technologies used for printing range of materials from metal to ceramics. In this study, we developed a customized 3D printer based on extrusion freeform fabrication technique, such as slurry deposition, for 3D printing of different molecular sieve zeolite monoliths like 3A, 4A, 5A and 13X to evaluate their performance in gas adsorption. The physical and structural properties of 3D printed zeolite monoliths will be characterized along with the gas adsorption performance. The BrunauerEmmett-Teller (BET) test of 3D printed samples will be performed for calculation of the surface area, which will give us the capacity of gas absorption into 3D printed zeolite. The BET surface area test showed good results for Zeolite $13 \mathrm{X}$ compared to available literature. The surface area calculated for $3 \mathrm{D}$ - printed Zeolite $13 \mathrm{X}$ was $767 \mathrm{~m}^{2} / \mathrm{g}$ and available literature showed $498 \mathrm{~m}^{2} / \mathrm{g}$ for $3 \mathrm{D}$ - printed Zeolite $13 \mathrm{X}$. The microhardness values of $3 \mathrm{D}$ - printed Zeolite samples were measured using a Vicker hardness tester. The hardness value of the $3 \mathrm{D}$ - printed Zeolite samples increased from $8.3 \pm 2$ to $12.5 \pm 3 \mathrm{HV}_{0.05}$ for Zeolite $13 \mathrm{X}, 3.3 \pm 1$ to $7.3 \pm 1 \mathrm{HV} 0.05$ for Zeolite $3 \mathrm{~A}, 4.3 \pm 2$ to $7.5 \pm 2 \mathrm{HV}_{0.05}$ for Zeolite $4 \mathrm{~A}, 7.4 \pm 1$ to $14.0 \pm 0.5 \mathrm{HV}_{0.05}$ for Zeolite $5 \mathrm{~A}$, before and after sintering process, respectively. The SEM analysis was performed for 3D printed samples before and after sintering to evaluate their structural properties. The SEM analysis reveals that all 3D - printed Zeolite samples retained their microstructure after slurry preparation and also after the sintering process. The porous nature of $3 \mathrm{D}$ - printed Zeolite walls was retained after the sintering process.
\end{abstract}

This is the author's manuscript of the article published in final edited form as:

Hawaldar, N., Jung, Y., Zhang, J., \& Park, H. (2018, January 1). Extrusion-Based 3D Printing of Molecular

Sieve Zeolite for Gas Adsorption Applications. 33-40. https://doi.org/10.7449/2018mst/2018/mst_2018_33_40 


\section{Introduction}

Additive manufacturing (AM) or 3D printing techniques are on the urge of today's manufacturing world due to their capability to produce components with complex geometry in relatively short time. Considering decades of research and advancement in AM techniques, different 3D - printed technologies were invented for metals, plastics, polymers, ceramics, glass, and sand. The crude oil, coal, and gas are the main energy resources available in the world. When we burn fossil fuels to obtain energy, carbon dioxide is produced instantaneously[1]. The concentration of carbon dioxide in the atmosphere has been increasing, due to the burning of fossil fuels to obtain energy, which is generally believed to increase the temperature of the Earth[2].Currently, researchers are working on developing 3D printers for some inorganic material like Zeolite.[3, 4]. Basically, these materials are used in separation, adsorption, reaction and storage of various industrial gases like carbon dioxide, [5] nitrogen, and hydrogen. Zeolites are naturally found in inorganic crystalline structures with multidimensional channel systems. It was discovered by mineralogist A.F. Cronstedt in 1976 which when heated, appeared to boil due to very fast water loss.[6] Adsorption is a surface phenomenon in which the atoms, molecules, and ions of gas, liquid or sometimes dissolved solids adhere to the surface creating a film of the adsorbate on the surface of the adsorbent. Adsorption can also occur at the interface of a condensed and a gaseous phase.[7] The amount or capacity of any material to adsorb is generally calculated by the surface area of a material. BET theory is used to calculate the surface area of the material.

\section{Extrusion-based 3d printing of Zeolite}

\subsection{Introduction}

Extrusion is a manufacturing process in which an object is created of the fixed cross-sectional profile. A material is pushed through a die or an extruder of the desired cross-section. [8] We can extrude materials ranging from metals, alloy metals, plastics, ceramics, and some advanced materials like metal-ceramic composites, metal-organic frameworks. Extrusion is mostly used for making plastic and metal parts, as it can be molded into different shapes easily by applying heat. But on the other hand, considering physical and microstructural properties of ceramics and composite materials it is hard to extrude by just applying heat. So the easiest option for extruding such materials is making slurry (paste) by adding binders and then as per application we can do post processes like sintering.

\subsection{Experimental section}

\subsubsection{Slurry preparation of Zeolite $13 \mathrm{X}$ and $5 \mathrm{~A}$}

The slurry preparation starts with mixing the ingredients with correct proportion which then will be loaded into an extruder for 3D printing. The mixing of chemical binders will be carried out at room temperature. Separate slurries were prepared for Zeolite 13X, 5A, 4A and 3A referring previous work done for the slurry preparation of Zeolite 13X and 5A [3]. The Zeolite 13X (Advanced Speciality Gas Equipments) and 5A (D.B.Becker) mixed with bentonite clay (Sigma - Aldrich) as a binder, methyl cellulose (DOW Chemicals) as a plasticizing organic binder, and poly(vinyl) alcohol (PVA) (ACROS Organics) as a co-binder. The hydroxyl groups from methyl cellulose contribute to additional particle cohesion which helps for Zeolite monolith strength. The magnetic stirrer (Fisher Scientific) was used 
at $1200 \mathrm{rpm}$ to mix the powders. This helped to form a homogeneous mixture of powders, which results in bubble-free slurry formation. After obtaining a homogeneous powder mixture, the homogeneous powder mixture was divided into small batches of 5 grams. Sufficient amount of DI water was added and mixed at $1200 \mathrm{rpm}$ till homogenous aqueous slurry with suitable viscosity was achieved. Every 30 min we added 5 grams of powder mixture along with DI water to maintain the viscosity of the slurry. The molecular sieve Zeolite $13 \mathrm{X}$ and $5 \mathrm{~A}$ have a pore diameter of $8 \AA$ and $5 \AA$ respectively but Zeolite $3 \mathrm{~A}$ and $4 \mathrm{~A}$ have a pore diameter of $3 \AA$ and $4 \AA$ respectively. As pore diameter of any molecular sieve Zeolite plays an important role in gas adsorption and separation property, we need to consider it while preparing the slurry and further implementation of gas separation and adsorption applications. The compositions of all the chemicals that will be used are shown in Table. I. Compared to the Zeolite $13 \mathrm{X}$ and $5 \mathrm{~A}$ we increased the weight percent loading in case of Zeolite 3A and 4A slurry preparation. Apart from this, all the procedure remains same.

Table I Composition of the 3D -Printed Zeolite 3A \& 4A Monoliths

\begin{tabular}{|c|c|c|c|c|}
\hline Monolith & $\begin{array}{c}\text { Zeolite } \\
\text { (wt \%) }\end{array}$ & $\begin{array}{c}\text { Bentonite clay } \\
\text { (wt \%) }\end{array}$ & $\begin{array}{c}\text { Methyl cellulose } \\
\text { (wt \%) }\end{array}$ & $\begin{array}{c}\text { PVA } \\
\text { (wt \%) }\end{array}$ \\
\hline 1 & 90 & 7 & 2.0 & 1.0 \\
2 & 95 & 3 & 1.5 & 0.5 \\
\hline
\end{tabular}

\subsubsection{D printing of Zeolite slurry}

A circular grated disc and a square grated design were chosen to be the geometric shape for our prints as the samples will be further used for gas adsorption tests. The circular grating disc with $15 \mathrm{~mm}$ diameter and 5mm thickness was designed in Creo Parametric and then converted into a .stl file for input to a 3D printer. The 3D printing of Zeolite slurry was initially done by hand extrusion through a $30 \mathrm{ml}$ syringe with $0.50 \mathrm{~mm}$ diameter needle to check the viscosity of the slurry. As per the literature available we performed multiple trails to get the desired viscosity, by changing amount of DI water added to make the slurry. During our first trial for Zeolite 5A we were not able to get desired viscosity of the slurry. We can see some amount of shrinkage of 3D - printed samples after drying at room temperature. For second trail we reduced the amount of DI water and loaded $2 \mathrm{~g}$ powder mixture per 30 mins. The slurry was stirred 1 hour extra for the second trial. Fig. 1 shows the 3D - printed zeolite samples for second trails. During second trail we printed square grate sample along with the circular grate.

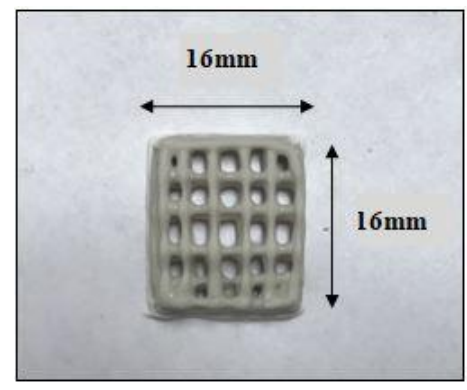

(a) Circular grate

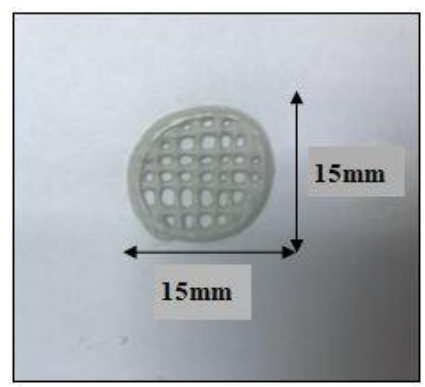

(b) Square grate

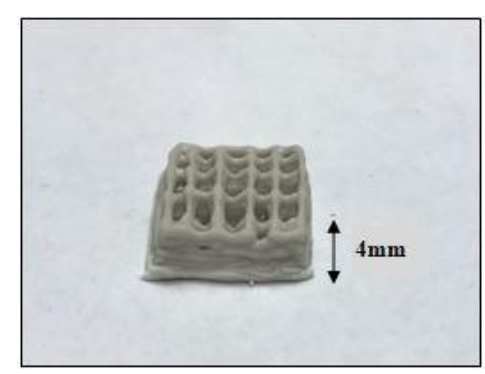

(c) Side view of the square grate

Figure 1. 3D - printed Zeolite 5A - Second trail 
Some amount of shrinkage in size for both the samples i.e. square and circular was observed after the drying at room temperature. After achieving the desired viscosity we decided to print using the customized 3D printer. Before loading the Zeolite slurry into the extruder, we performed dry run tests to prevent flaws and to avoid the wastage of slurry. The dry run test helped us to adjust the distance between extruder and bed. We successfully printed samples of Zeolite 13X, 3A and 4A using the customized 3D printer which is shown in Fig. 2
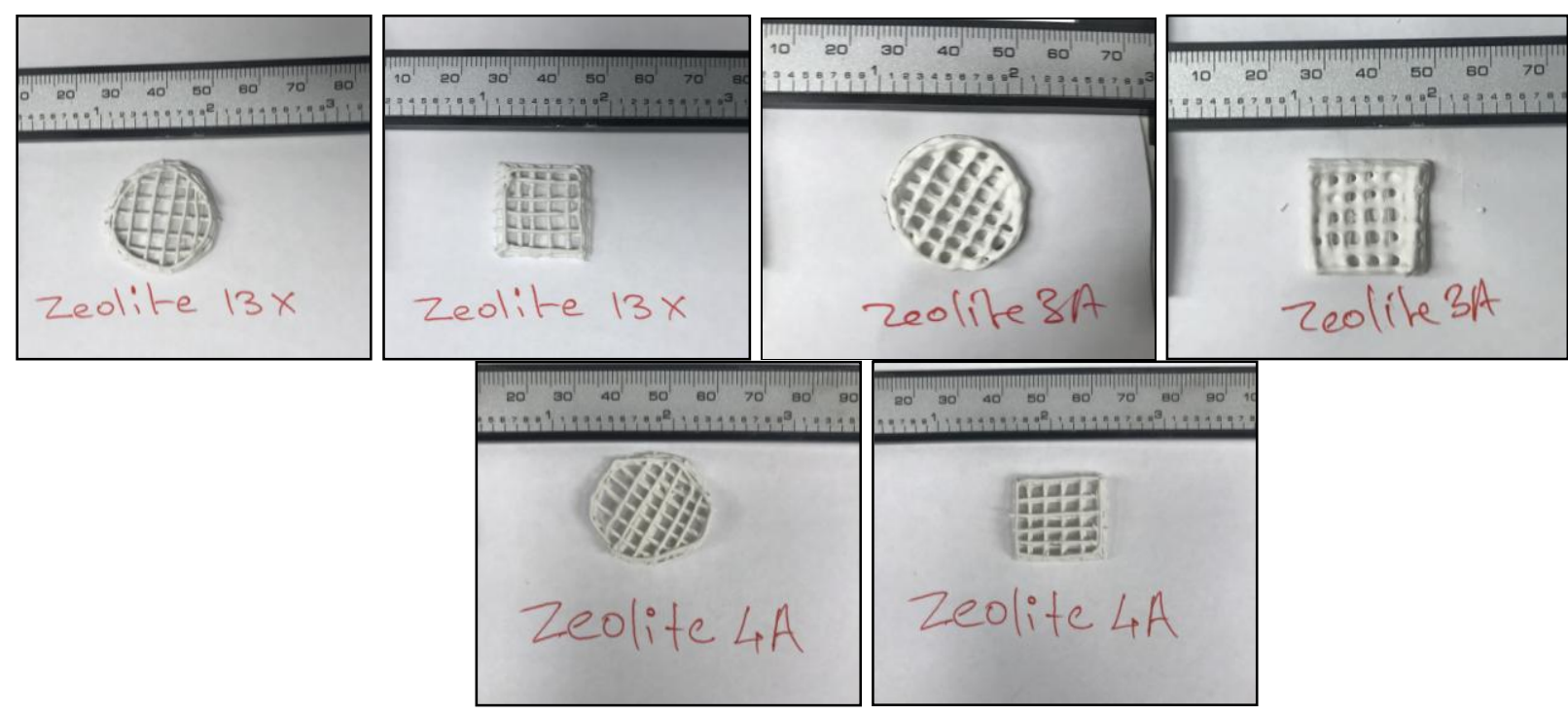

Figure 2. 3D - printed Zeolite samples

\subsubsection{Sintering of 3D - printed Zeolite}

The 3D - printed Zeolite samples will be initially dried at room temperature to partially remove the present water content. To allow the polymer linker (PVA) and methyl cellulose to accumulating high strength and to avoid skin cracking the 3D - printed samples were placed into an oven (GSL 1600X, MTI corporation) and heated at $100{ }^{\circ} \mathrm{f}$ which will remove the remaining water content. After heating into an oven at $100^{\circ} \mathrm{f}$ the $3 \mathrm{D}$ - printed samples were sintered in a temperature controlled furnace at $700{ }^{\circ} \mathrm{C}$ at the rate of $20{ }^{\circ} \mathrm{C} / \mathrm{min}$ for $2-4 \mathrm{hr}$. This will help in decomposing and remove the co-binder, methyl cellulose, and PVA. Sintering removes the organic content which results in increased mesoporosity of the 3D - printed Zeolite sample, in addition also enhances the mechanical strength of the 3D - printed Zeolite. After sintering was done at $700^{\circ} \mathrm{C}$ the Zeolite samples were cooled at room temperature. Fig. 3 (a) shows the Zeolite 4A square grate sample after being sintered. Some amount of shrinkage was seen after sintering along with some cracks which are shown in Fig. 3 (b) some amount of cracking was seen for all the 3D - printed Zeolite samples after sintering.

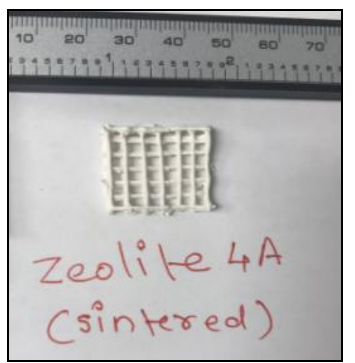

(a)

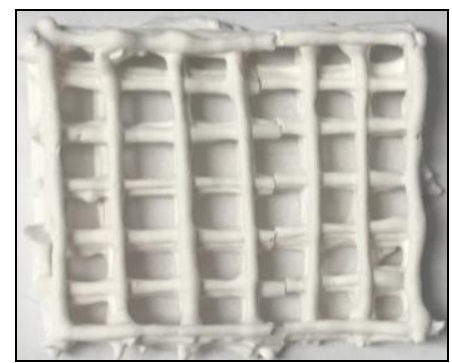

(b)

Figure 3. Zeolite 4A sample (sintered): (a) Square grate (b) Magnified image 


\subsubsection{Characterization of Zeolite Monolith}

We calculated the surface area of 3D - Printed Zeolite 13X monolith samples using the gas analyzer (Quantachrome Instruments). Physisorption isotherms of N2 were collected at 77K for determining the textural properties of 3D printed Zeolite 13x monoliths. Degassing of all the 3D printed sample was carried out before all the measurements using degassing equipment (Autosorb iQ Station 2, Quantachrome Instruments) at $300^{\circ} \mathrm{C}$ for $3 \mathrm{~h}$. Structural morphology of 3D - printed Zeolite samples was studied using scanning electron microscope (SEM).(JEOL Model JSM-5610, Tokyo, Japan)

\subsubsection{Mechanical testing}

The microhardness of 3D - printed Zeolite samples before and after sintering were calculated using Vickers hardness test. We selected microhardness test due to the size and geometry of the 3D - printed Zeolite samples. The Vicker hardness tester (Model 900-391, Phase II, Upper Saddle River, NJ, USA) was used for measuring the microhardness. The specimens for hardness test were prepared using a hot mounting press (EQ-MP-300 Mounting Press, MTI Corporation). The indentation tests for Vicker hardness test were performed on the top surface of the mounting specimen at room temperature. The indentation was done at load for $15 \mathrm{sec}$. The indent mark for Zeolite 3A sample before sintering is shown in Fig.4

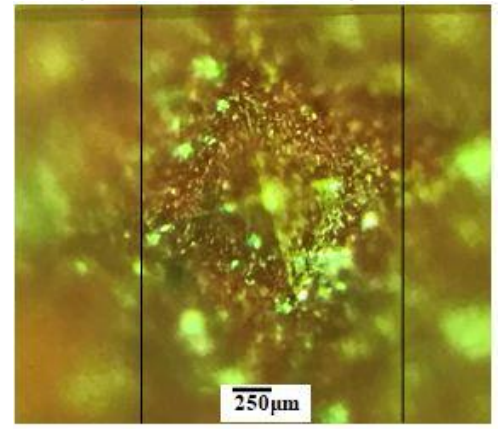

Figure 4. Indent mark

\section{Results and discussion}

\subsection{Physical properties of 3D- printed Zeolite}

Physisorption isotherms of $\mathrm{N} 2$ collected at $77 \mathrm{~K}$ of 3D printed Zeolite $13 \mathrm{x}$ monoliths showed uptake at low partial pressure $\left(\mathrm{P} / \mathrm{P}_{\mathrm{o}}\right)$ as per Fig. 5 which clearly indicated the adsorption in the micropores of Zeolite 13X.The gradual increase of uptake at high $\mathrm{P} / \mathrm{P}_{\mathrm{o}}$ with the hysteresis was seen, indicates the capillary condensation in mesopores. [9] The BET surface area for 3D printed Zeolite 13X was found out to be $767.429 \mathrm{~m}^{2} / \mathrm{g}$, using a Multi-Point BET plot shown in Fig. 6 


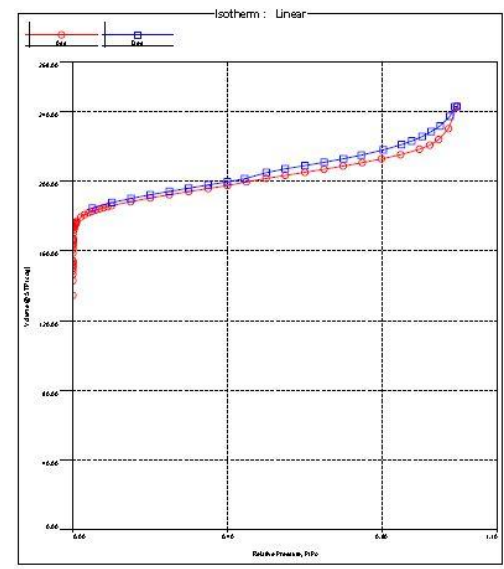

Figure 5. N2 physisorption isotherm for 3D printed Zeolite 13X

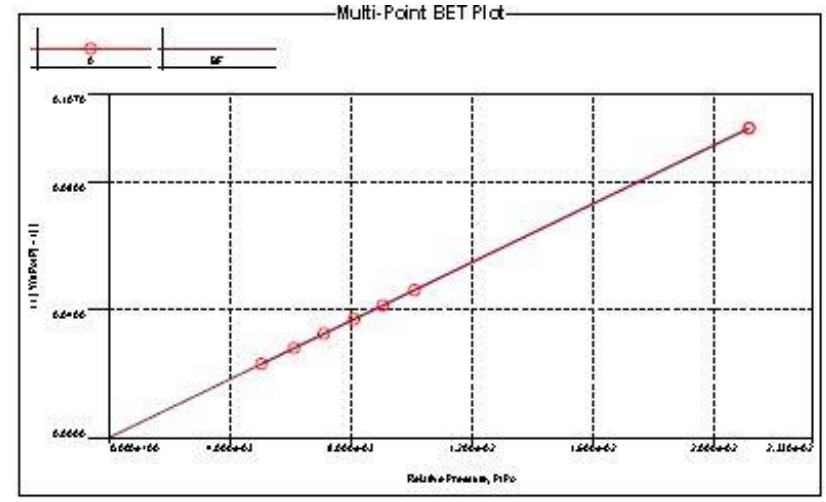

Figure 6. Multi-point BET plot of Zeolite 13X

\subsection{Structural properties of 3D - printed Zeolite}

Microstructure and composition of the 3D-printed zeolite samples before and after sintering were analyzed using SEM. SEM images with low- magnification and high-magnification for 3D printed Zeolite 3A, and 4A, samples before sintering (a-f) and after sintering (g-l) are shown in Fig. 7 and Fig. 8. respectively. The SEM image is shown in Fig. 7 (i) and (j) of Zeolite 3A particles at $5 \mu \mathrm{m}$ shows more cohesiveness of particles after sintering which resulted in increased strength. The magnified view of the channel structure is shown in Fig. 7 (c) and (d) for Zeolite

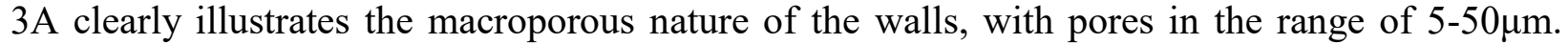
Visual comparison of the SEM image at $2.5 \mu \mathrm{m}$ shows that the particle shape of all the Zeolite at green state was nearly cubical except for Zeolite $13 \mathrm{X}$ which was rather more irregular. Moreover, the SEM images of 3D - printed Zeolite samples indicate that the particle distribution was even and not disturbed after vigorous stirring during slurry preparation and some particle agglomeration was observed after sintering. The sintered bodies were easily broken compared to the green bodies, indicating the post-heat treatment should be controlled to give some mechanical properties to the sintered body. The phase did not change after sintering in all samples. It was hard to find the difference in the microstructure, composition, and phase before and after heat treatment.
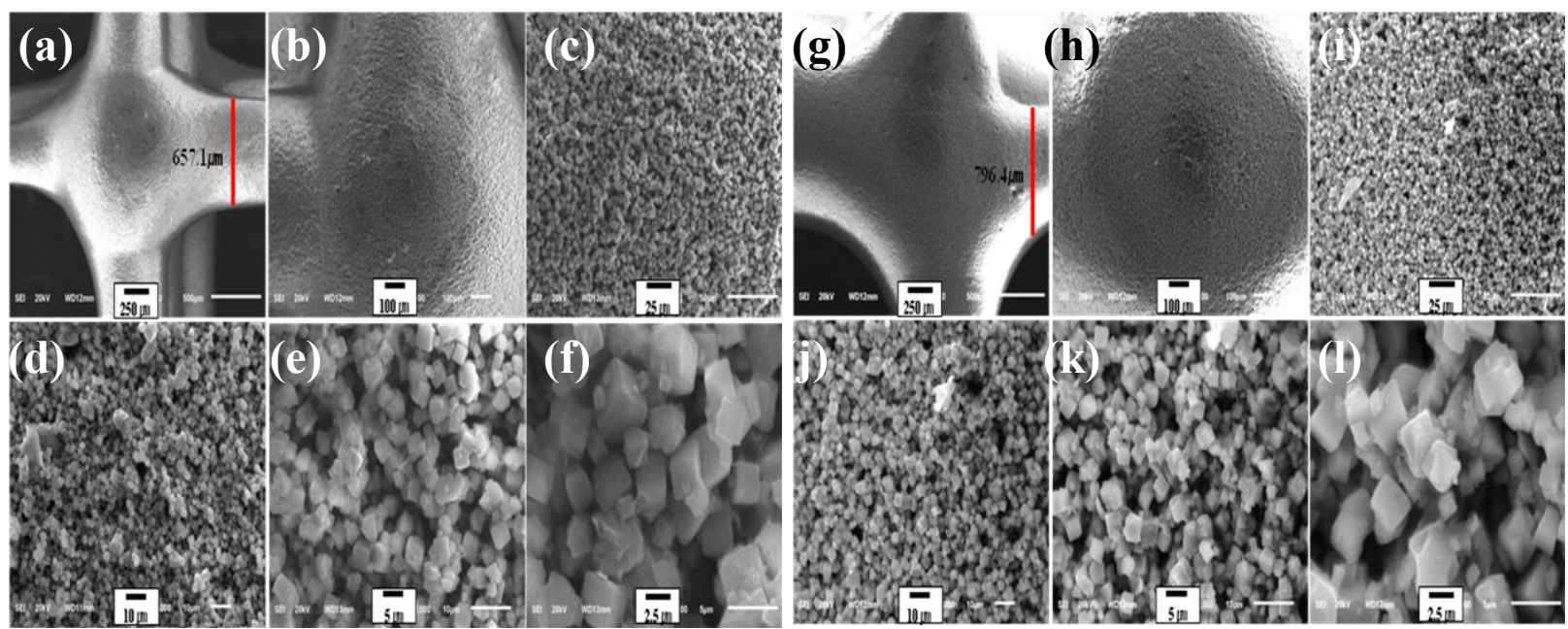

Figure 7: SEM Images of (a-f) green state Zeolite 3A and (g-l) sintered Zeolite 3A 3D - printed monoliths 

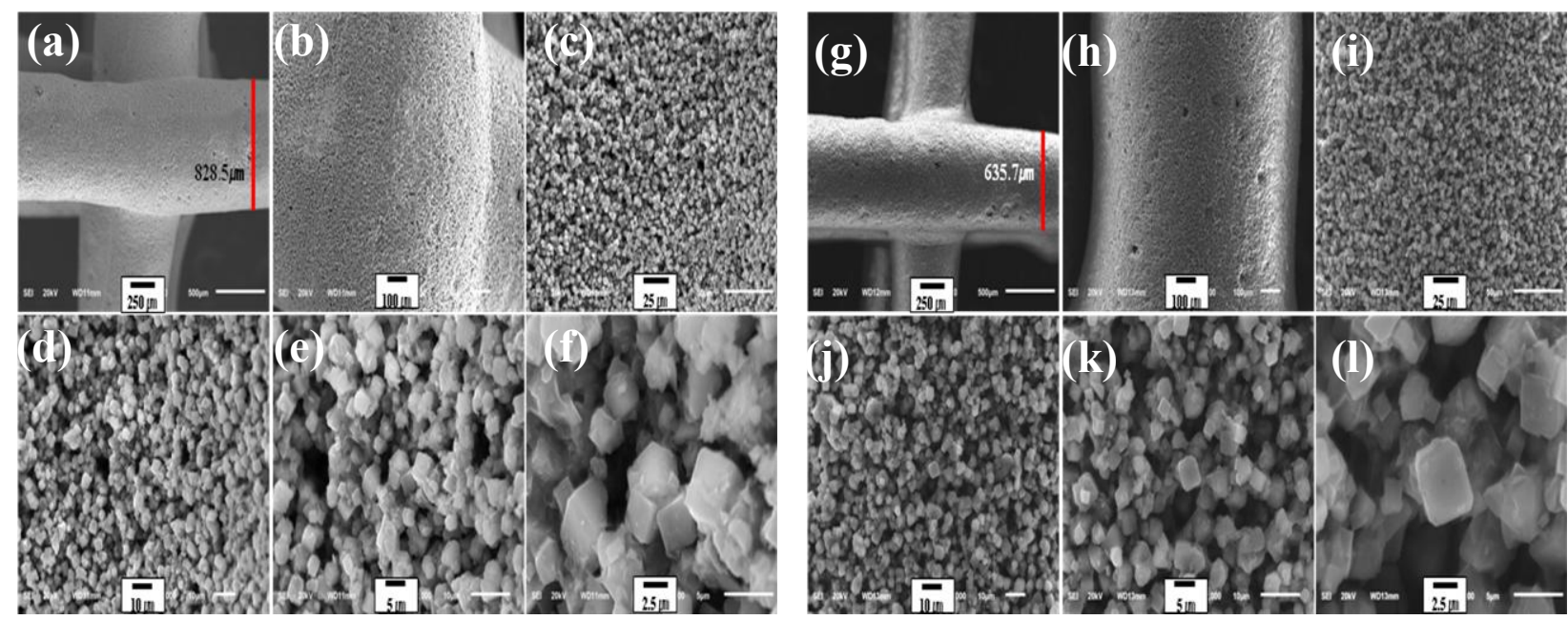

Figure 8: SEM Images of (a-f) green state Zeolite 4A and (g-l) sintered Zeolite 4A 3D - printed monoliths

\subsection{The mechanical strength of 3D - printed Zeolite}

To determine the standard deviation of the hardness value we conducted five indentations on the mounting specimen. The Vicker hardness values of unsintered and sintered 3D - printed Zeolite samples are shown in Table II. The standard deviation of microhardness values of both unsintered and sintered Zeolite samples are shown in Fig. 9 As shown in the chart the hardness of 3D - printed Zeolite samples increased from $8.3 \pm 2$ to $12.5 \pm 3 \mathrm{HV}_{0.05}$ for Zeolite $13 \mathrm{X}, 3.3 \pm$ 1 to $7.3 \pm 1 \mathrm{HV}_{0.05}$ for Zeolite $3 \mathrm{~A}, 4.3 \pm 2$ to $7.5 \pm 2 \mathrm{HV}_{0.05}$ for Zeolite $4 \mathrm{~A}, 7.4 \pm 1$ to $14.0 \pm 0.5$ HV 0.05 for Zeolite $5 \mathrm{~A}$ respectively. Sintering is a most effective process of increasing the strength of 3D - printed Zeolite samples, as we see from the values from Table. II in all the Zeolites samples hardness was increased after the sintering process.

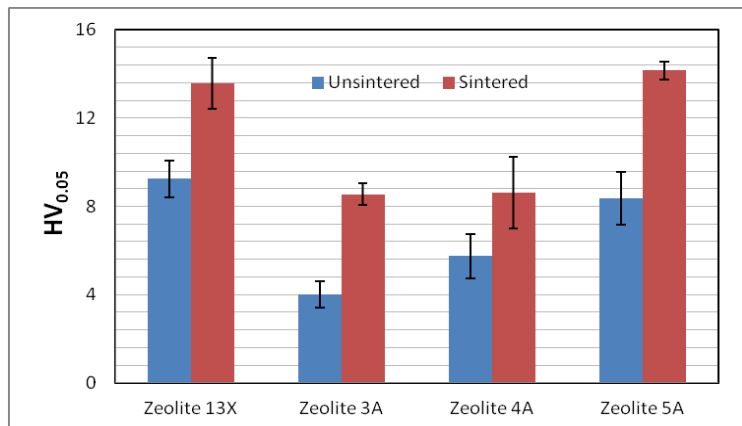

Figure 9. Vicker hardness values, $\mathrm{HV}_{0.05}$, of the 3D - printed Zeolite samples

Table III. Vicker Hardness Test of 3D - printed Zeolite Samples

\begin{tabular}{|c|c|c|c|c|c|c|c|}
\hline \multicolumn{2}{|c|}{ Zeolite 13X } & \multicolumn{2}{c|}{ Zeolite 3A } & \multicolumn{2}{c|}{ Zeolite 4A } & \multicolumn{2}{c|}{ Zeolite 5A } \\
\hline Unsintered & Sintered & Unsintered & Sintered & Unsintered & Sintered & Unsintered & Sintered \\
\hline 8.33 & 14.49 & 3.38 & 8.92 & 5.18 & 7.60 & 7.49 & 14.67 \\
9.05 & 13.21 & 3.42 & 8.33 & 4.35 & 8.58 & 6.90 & 14.31 \\
9.22 & 12.45 & 4.68 & 7.84 & 6.63 & 9.56 & 8.74 & 13.53 \\
10.61 & 15.05 & 4.20 & 9.04 & 5.84 & 6.57 & 9.90 & 14.03 \\
8.98 & 12.6 & 4.44 & 8.61 & 6.72 & 10.77 & 8.78 & 14.21 \\
\hline
\end{tabular}




\section{Conclusion}

a) The slurries of Zeolite $3 \mathrm{~A}$ and $4 \mathrm{~A}$ were successfully synthesized same as Zeolite $13 \mathrm{X}$ and $5 \mathrm{~A}$.

b) Grated structure of Zeolite $3 \mathrm{~A}$ and $4 \mathrm{~A}$ was able to print using the customized $3 \mathrm{D}$ printer.

c) The BET surface area calculated for $3 \mathrm{D}$ printed Zeolite $13 \mathrm{X}$ was $767 \mathrm{~m}^{2} / \mathrm{g}$ and comparing it with an available literature BET surface area of $770 \mathrm{~m}^{2} / \mathrm{g}$ we can conclude that the $3 \mathrm{D}$ printed Zeolite $13 \mathrm{X}$ has better gas adsorption performance.

d) Based on SEM results we can conclude that the microstructure of 3D - printed Zeolite Type $\mathrm{X}$ and Type A was maintained.

e) The microhardness of Zeolite samples before and after sintering was calculated. The hardness values are $8.3 \pm 2$ to $12.5 \pm 3 \mathrm{HV}_{0.05}$ for Zeolite $13 \mathrm{X}, 3.3 \pm 1$ to $7.3 \pm 1 \mathrm{HV}_{0.05}$ for Zeolite $3 \mathrm{~A}, 4.3 \pm 2$ to $7.5 \pm 2 \mathrm{HV}_{0.05}$ for Zeolite $4 \mathrm{~A}, 7.4 \pm 1$ to $14.0 \pm 0.5 \mathrm{HV}_{0.05}$ for Zeolite $5 \mathrm{~A}$ respectively.Sintering resulted in an increase in hardness value for the entire $3 \mathrm{D}$ - printed sample.

f) Some particle agglomeration was observed after sintering which is due to binder residual. This binder residual will affect the mechanical strength of the final sample as they will be responsible for the change in microstructure.

g) Increased hardness value after sintering is an indication of the better mechanical strength of $3 \mathrm{D}$ - printed Zeolite samples. But on the other hand, increased hardness value after sintering made them brittle, it suggests that the sintering temperature need to be optimized along with the printing parameters.

\section{References}

1. Cheung, O., Narrow-pore zeolites and zeolite-like adsorbents for CO2 separation. 2014, Department of Materials and Environmental Chemistry (MMK), Stockholm University.

2. Vitousek, P.M., Beyond global warming: ecology and global change. Ecology, 1994. 75(7): p. 1861-1876.

3. Thakkar, H., et al., 3D-printed zeolite monoliths for CO2 removal from enclosed environments. ACS applied materials \& interfaces, 2016. 8(41): p. 27753-27761.

4. Thakkar, H., et al., 3D-Printed Metal-Organic Framework Monoliths for Gas Adsorption Processes. ACS applied materials \& interfaces, 2017. 9(41): p. 35908-35916.

5. Boot-Handford, M.E., et al., Carbon capture and storage update. Energy \& Environmental Science, 2014. 7(1): p. 130-189.

6. $\quad$ Baerlocher, C., L.B. McCusker, and D.H. Olson, Atlas of zeolite framework types. 2007: Elsevier.

7. McNaught, A.D. and A.D. McNaught, Compendium of chemical terminology. Vol. 1669. 1997: Blackwell Science Oxford.

8. Drozda, T.J., Tool and manufacturing engineers handbook: machining. Vol. 1. 1983: Society of Manufacturing Engineers.

9. Akhtar, F. and L. Bergström, Colloidal processing and thermal treatment of binderless hierarchically porous zeolite $13 \mathrm{X}$ monoliths for CO2 capture. Journal of the American Ceramic Society, 2011. 94(1): p. 92-98. 